\title{
Perspectivas da performance docente à luz das tecnologias digitais
}

\section{Perspectives of teaching performance in thelight of digital technologies}

\author{
Elaine Conte*
}

\begin{abstract}
RESUMO
A performance surge nesse ensaio como uma dimensão inquietante e complexa, para compreendermos a dinâmica das relações do viver fluído e intenso das interconexões digitais, considerando a emergência da tecnociência e do agir pedagógico online. Trata-se de aprofundar os debates hermenêuticos sobre as dimensões da performance docente com as transformações objetivas, subjetivas e sociais das redes sociais. Afinal, o que estamos performando em termos de ações pedagógicas, filosóficas e políticas na cultura digital? Os desafios de uma performance docente aliada à cultura digital revelam déficits acerca da recriação de conhecimentos e atuação performativa do professor na areia movediça das tecnologias. Tais provocações da atuação docente na cibercultura apontam para ambiguidades dos processos pedagógicos nos meios virtualizados, o que demanda um processo de reflexão que possa se expandir com potencial de conversação, potencial de visibilidade e contradições performativas. Uma visão crítica da pedagogia online com contrapontos e desdobramentos no exercício da imaginação e da produção de conhecimentos requer a ação docente para engajar-se às performances sociais, a partir de outras releituras e pesquisas.

Palavras-chave: Performances. Tecnologias digitais. Redes sociais. Educação. Comunicação.
\end{abstract}

\begin{abstract}
The performance appears in this essay as a disturbing and complex dimension, to understand the dynamics of the relationships of the fluid and intense living of digital interconnections, considering the emergence of
\end{abstract}

"Universidade La Salle. Canoas, Rio Grande do Sul, Brasil.E-mail: elaineconte@yahoo.com.brhttp://orcid.org/0000-0002-0204-0757 
technoscience and online pedagogical action. It is a question of deepening the hermeneutic debates about the dimensions of the teaching performance with the objective, subjective and social transformations of the social networks. After all, what are we performing in terms of pedagogical, philosophical and political actions in digital culture? The challenges of a teaching performance allied to the digital culture reveal déficices about the recreation of knowledge and performative performance of the teacher in the quicksand of technologies. Such provocations of the teaching activity in cyberculture point to ambiguities of the pedagogical processes in the virtualized media, which demands a process of reflection that can expand with potential for conversation, potential visibility and performative contradictions. A critical view of online pedagogy with counterpoint and unfolding in the exercise of imagination and the production of knowledge requires the teaching action to engage in social performances, from other re-readings and researches.

Keywords: Performances. Digital technologies. Social networks. Education. Communication.

\section{Introdução}

A performance do professor na contemporaneidade é um tema controverso e ambíguo, mas que desperta nos processos socioeducativos e nas experiências formativas inúmeras tensões, complexidades e movimentos dialéticos de reinvenção da práxis no tempo e no espaço. Desde os tempos mais antigos, sempre houve uma performance, cujo caráter não era teórico-científico, mas correspondia e servia muito mais às artes de fazer, de procedimento prático e estético-expressivo (CONTE, 2013). Viver a radicalização da conversação na esteira das transformações tecnológicas digitais é o que nos une para compreender as performances em rede, que transpõem e subvertem o espaço público e o privado na contemporaneidade. A performance docente nesse sentido assume a expressão construída por Mallmann (2008, p. 22):

Em EaD, os modos de saber, ser, querer, poder e fazer transformam-se pela cooperação, interação, autonomia, problematização e investigação necessárias ao movimento docente que se intensifica nas interações em equipes. No contexto dessa investigação, denomina-se as implicações e inferências desse movimento múltiplo de performance docente. A performance docente diz respeito ao trabalho docente realizado em cada 
uma das etapas cíclicas (retrospectivas e prospectivas) de planejamento, implementação, avaliação e replanejamento da mediação pedagógica sustentada pelos materiais didáticos impressos e hipermidiáticos.

Nosso acesso a uma suposta realidade é sempre mediado por ações políticas, sociais e de discursos, que não apenas a representam, mas falam dela e a instituem de forma humanista ou determinista, projetando seus impactos em diferentes cenários e revelando problemas de homogeneização e novas patologias (HABERMAS, 1999). Como veremos, com a democratização das tecnologias digitais em rede tendemos a usá-las como modus operandi para o convívio social (daquele que performa um personagem onde tem sempre alguém olhando), uma vez que as linguagens mediadas pelas tecnologias são complementares às conversações presenciais. Se a performance surge de uma ação linguística e humana no mundo presente, então, no horizonte das transformações ilimitadas e reduzidas do caráter interpretativo e crítico da própria trajetória, as práticas pedagógicas em ambientes online surgem como uma questão importante nesse debate, uma vez que afetam e dão visibilidade aos processos de construção (inter)subjetivos. O próprio horizonte performativo do professor parece que se aloja na difusa e ambivalente fronteira do ilimitado das tecnologias em transição para as redes digitais.

Na verdade, a internet além de dar visibilidade a personagens reais coloca em crise a interioridade dos sujeitos, uma vez que a personalidade passa a ser dirigida e orientada para os outros. Nesse sentido, o que era um traço da intimidade humana passa a fazer parte do espaço público como uma extimidade, agora teatralizada e visualizada, num espetáculo sedutor e permanente das tecnologias digitais (SIBILIA, 2008). Na era da digitalização universal, os lentos ritmos do pensar e refletir pedagógicos passam a ser intimidados pelas pressões dos prazeres e dos aprimoramentos digitais do instrumental onipotente da tecnociência. Nesse horizonte de descompassos e abismos à moldagem de corpos e subjetividades lateja o desejo do professor em direção a novas performances compatibilizadas com o horizonte digitalizado (SIBILIA, 2008). Também, a pressa institucionalizada no leque abundante do virtual contempla a abolição das distâncias geográficas e seduz os professores com o discurso de uma economia de tempo e trabalho. Desse cenário brotam novas performances totalitárias do mercado que seduzem para uma economia do conhecimento e para um "solucionismo" pedagógico que faz decair as performances necessárias para perguntar e narrar o que somos. Parece que, 
[...] já não nos construímos prioritariamente em torno daquele núcleo considerado interior, oculto e misterioso, embora mais verdadeiro e sólido que tudo o que os demais podem enxergar. Em vez disso, a definição de quem é cada um parece emergir, cada vez mais, do que se vê. Essa categoria inclui não só o aspecto físico e tudo aquilo que costumava ser considerado "vãs aparências" diante da contundência da "beleza interior", mas também os próprios atos que se expõem ao olhar alheio. Em suma: não apenas a cobiçada imagem de si que cada sujeito consegue projetar, mas também a performance da própria vida. Por isso, considerando a crescente importância dessa visibilidade na construção do eu e no compartilhamento do que se é, não surpreende que nos últimos anos tenham proliferado as vitrines midiáticas e artísticas destinadas a canalizar tais demandas (SIBILIA, 2015, p. 141).

Daí a complexidade desse conflito em cena, pois as tecnologias incorporadas às redes sociais ${ }^{1}$ são adaptadas à vida humana de forma ativa como um modo de produção, expressão e participação em todas as instâncias sociais. As formas de conexão via internet em ambientes virtuais de participação interativa atestam que vivenciamos a dinâmica hiperconexão, que transforma o estar conectado em ser conectado (SANTAELLA, 2013). A conexão instantânea, especialmente pelo celular, integra a realidade presencial em que vivemos com interesses particulares e podem trazer repercussões nas relações educativas, incorporando um sistema de trocas mobilizadas por reformadores empresariais, capazes de popularizar e reprogramar aspectos das subjetividades e das sociabilidades. Quando se fala algo na internet se reinventa e se renova esta criação, em um horizonte de conversação que hoje se espalha pelas redes online em campos de força sociais. Mas, com as possibilidades de diálogos ilimitados se expandiram também novas formas de experiências comunicativas para as quais ainda não temos à disposição as condições apropriadas para avaliar se há de fato aprendizagens e para pensar direções dentro dos próprios limites de um tempo de dispersões em uma bolha digital desorientada (HAN, 2017). Nesse caso, como manter as performances pedagógicas atualizadas com esses novos processos de transação de conhecimento e aliadas à cultura digital? Será que o professor perdeu a visibilidade no exercício da imaginação e da produção de conhecimentos ou poderá explorar as brechas do sistema e engajar-se com as performances sociais?

Vale enfatizar que ao voltarmos nosso olhar para a palavra hermenêutica, encontramos diversos significados, que são ilustrados e definidos historicamente, e vão desde a arte de interpretar os livros sagrados, os textos 
antigos, os sinais e os símbolos da cultura. Na verdade, a hermenêutica reconfigura a interdependência linguística, que reconhece a voz do outro e implica reconstrução aberta à interpretação contextualizada, privilegiando os discursos dos sujeitos, de onde brotam novos sentidos expressivos à apropriação dos estudos históricos (SIDI; CONTE, 2017, p. 1943).

A linguagem performativa só se define pela presença do outro (pela diferença e reconhecimento da alteridade) e tem força estética, social, ética, política, epistemológica, que Habermas chama de força emancipatória. Posto o debate na dinâmica da cultura digital e da performance pedagógica, examinamos alternativas a uma reconstrução dos saberes pedagógicos para superar os equívocos do reducionismo cognitivo-instrumental, que bifurca a razão performática em si quando seu emprego se desloca da experiência formativa de nossa época. $\mathrm{O}$ sentido do termo racionalidade, de Habermas (1990, p. 69), "não tem tanto a ver com a posse do saber, mas com o modo como os sujeitos capazes de falar e agir empregam o saber", conferindo uma dimensão metamorfoseante e cognitiva à ação performativa. A linguagem impulsiona e apela à interação e à necessidade de ser entendido, adquirindo grande força emocional pelos meios digitais, visto que seduzem ao agir com e para o outro que nos interpela e, ao mesmo tempo, revela abismos sob uma sensação ilusória de conexão com o mundo. A digitalização da própria vida em meio a essa nova imediaticidade de expectativas e de atualização permanente em que vivemos retroalimenta perigos e aflições nas atividades interpretativas e performativas globais. Assim, a ação performativa é a primeira exigência de um projetar-se no processo de socialização e democratização cultural, pois a fala restaura e anuncia o gérmen da renovação da vida. A rigor, torna-se pertinente perguntar: de que maneira a utilização de novos dispositivos de comunicação vem transformando as performances dos professores? Quais modificações educativas são necessárias para não recairmos na banalização desses meios? Podemos ignorar a força dos movimentos performativos em redes digitais? Quais são os potenciais para a ação no mundo virtual projetada no olhar do outro em redes de relações vigentes? De que tipo de performance necessitamos para alcançar o objetivo de aprendizagens evolutivas e reconstrutivas?

Para a compreensão da alquimia da performance do professor à luz das tecnologias digitais, o texto, de perspectiva hermenêtica, apresenta os potenciais educativos e sociais da conversação em rede, trazendo as aporias da performance no horizonte da tecnologização. Além disso, discute o potencial de visibilidade das interações sociais à educação online, tecendo algumas considerações finais sobre as contradições performativas da sociedade emergente. 


\section{A conversação em rede}

É preciso recuperar as potências sociais e formativas das tecnologias em meio aos perigos dos processos de tecnologização vigentes, afinal de contas, são "redes que nos capturam, que nos envolvem e nos transformam. [Redes que] nos aproximam, mas também nos deixam mais distantes uns dos outros, nos levam para dimensões sedutoras, coletivas, em tons ambíguos" (FERREIRA; ROSADO; CARVALHO, 2017, p. 2). Mas, como indaga André (2008, p. 55), "que condições têm o professor que atua nas escolas, para fazer pesquisas" e participar de processos de formação permanente por meio de reflexões mais aprofundadas como um pesquisador e agente de mudanças, que ressignifica conhecimentos, por perspectivas arraigadas cada vez mais em seu trabalho cotidiano? Se compartilhamos um suposto analfabetismo tecnológico de uma forma de vida moldada como informação e propagada como automodelação de vida, que encobre as performances pedagógicas, talvez a abertura de canais de comunicação, despertando novas recriações cooperativas, outros projetos e sentidos com as tecnologias digitais poderá resistir às adequações da sociedade do controle.

Embora nem todos os participantes da rede produzam conteúdos, o simples fato de ter acesso a esse mundo virtual, abrindo-se para interfaces sociais coletivas, já é um horizonte de autocriação e um abismo, um exercício de imaginação e uma possibilidade de aprender com novos tipos de narrativas ou ficções. Cada sujeito participante desenvolve uma maneira de uso e apropriação das redes sociais, passando a conviver com a presença digital das pessoas nesses contextos, respondendo e atuando com essa autoimagem virtual própria. Por isso, a participação nessas redes reforça a criação de uma identidade virtual, confere visibilidade e pode gerar momentos comunicativos por meio de conteúdos profissionais, de vínculos emocionais ou de opinião.

É uma cultura em que seus membros creem que suas contribuições importam e desenvolvem determinado grau de conexão social com o outro, de modo que tem grande relevo aquilo que os demais pensam ou se supõe que pensam sobre o que cada um cria, por mais insignificante que seja (SANTAELLA, 2013, p. 45).

Com essas mutações, o virtual não substitui o real, ele multiplica as oportunidades para a reatualização performática dos sentidos e significados no mundo, abrindo novas arquiteturas de vida e corporificando múltiplas linguagens. 
Para Le Breton (2009, p. 142), a virtualidade é um mundo "em que as fronteiras se misturam e em que o corpo se apaga, em que o outro existe na interface da comunicação, mas sem corpo, sem rosto, sem outro toque além do toque do teclado do computador, sem outro olhar além do olhar da tela". Assim, a performance virtual também é o local do encontro com o outro, onde todas as pessoas têm acesso ao saber, pela rede mundial de computadores, às formas de apreender e movimentar-se no mundo em transformação. Podemos afirmar que a pedagogia online é fruto da virtualidade, que se transforma a cada instante em função das relações humanas, que permite que a dinâmica da voz atinja uma alta velocidade que passa a ser ouvida no mesmo momento em que é proferida. De acordo com Nóvoa (2015, p. 20),

O trabalho dos professores deve ser apoiado e continuado por três movimentos. Primeiro, uma organização mais aberta e diversificada dos espaços e dos tempos escolares. Segundo, um currículo centrado nos alunos e em suas aprendizagens, e não em listas intermináveis de conhecimentos ou competências. Terceiro, uma pedagogia com dimensão fortemente colaborativa, que utilize a relação (as redes) como dispositivo de comunicação e aprendizagem.

A performance docente transita na relação entre o mundo da vida e o mundo virtual, especialmente na abordagem da pedagogia online, pois aparece como uma possibilidade de reconhecimento de novos movimentos dessa virtualidade que ganha sentidos no agir conversacional no mundo, na volatilidade dinâmica capaz de se transformar em relação com o outro sujeito. É nesta conexão viva online, que a ação performativa pode tornar-se uma potência criadora, inacabada e aprendente no mundo, pelo exercício do estranhamento e pelas provocações às mutações vigentes. De acordo com Sánchez Gamboa (2013, p. 57-58),

A tecnologia vem desenvolvendo-se, impulsionada pela necessidade de ampliar e aguçar a sensibilidade humana. Isto é, a tecnologia alarga as capacidades da percepção humana: por exemplo, ver mais longe, de forma mais fina, mais concentrada, ultrapassando limites, obstáculos e barreiras como falta de iluminação (telescópios, microscópios, raios-X, aparelhos de luz infravermelha, micro câmeras). Escutar melhor com ajuda das tecnologias, tais como radares, sonares, ultrassom. Sentir melhor através de sensores, da ressonância magnética etc. Outras tecnologias ajudam na memória e na organização de dados e de informações, como o moderno computador. Mas todas essas tecnologias não têm sentido se por trás delas não está uma sensibilidade atenta [...]. 
Nesse contexto de discussão, Vilém Flusser (1994, p. 33) afirma que "um erro muito difundido é achar que a máquina limita a liberdade do gesto, porque na verdade a máquina coloca em movimento as regras do próprio gesto". Especialmente no campo do conhecer e do aprender, o professor precisa guiar sua sensibilidade pedagógica para uma educação política e engajada, no sentido da necessidade de uma crítica permanente, potencializando as diferentes questões articuladas no desenvolvimento de inter-relações entre os sujeitos e a visão de totalidade (ADORNO, 1995).

Por meio da virtualidade da linguagem, que está ligada à multiplicidade de conhecimentos e expressões (polivocidade cultural), torna-se possível o agir pedagógico, gerando novos sentidos ao conhecer, que passa a ser problematizado na linguagem em movimento do conhecido para as novas formas de pensar. Essa cultura de participação que resulta em processos de reconstrução coletiva do conhecimento expandiu-se notavelmente em termos de pedagogia online e implica expor-se, criar, comunicar, trocar, socializar e colaborar com a "conversação em rede" (RECUERO, 2012). Se na interação face a face, o discurso é coproduzido, na conversação em rede é preciso, antes, apropriar-se dessas ferramentas mediadas, que são textuais, visuais, sonoras e possibilitam novas interconexões. No caso do Facebook, por exemplo, quando alguns atores passam a discutir uma mensagem, ela torna-se visível para os amigos dos debatedores mesmo que não estejam conectados ao autor principal da postagem da conversa, que também pode replicar essas interações incluindo os outros. Essas tendências flexíveis por meio do Facebook tornam mais fáceis a manutenção das conexões sociais já existentes e aproximam novos contatos (amigos), a partir de diferentes mundos virtuais.

A conversação é o principal elemento do cotidiano para legitimar a face construída culturalmente, em termos de atributos sociais aprovados na tradição cultura. Contraditoriamente, há um descrédito do valor de capital humano e social que é construído, pois as trocas são reduzidas e restritas ao próprio nicho de atuação de interesses econômicos, unidimensionais e mecânicos (RECUERO, 2012). Por tudo isso, as possibilidades da performance do professor online assumem um papel importante, uma vez que cresce a oferta de uma educação aberta (de poder e saber imaterial) e esta precisa ser problematizada em termos de ação comunicativa no mundo. A partir desses elementos, não cabe utilizar apenas uma perspectiva ativista e da neutralidade política (ignorando a dimensão da práxis performativa e crítica), mas o professor necessita de uma presença em meio às tecnologias, uma atuação comunicacional e colaborativa de aprendizagem, sem ficar refém das patologias da técnica ou do não agir. Nesses termos, 
A educação online acontece cada vez mais em situações bem amplas e diferentes, da educação infantil até a pós-graduação, dos cursos regulares aos cursos corporativos. [...] A educação online não equivale à educação a distância. Um curso por correspondência é a distância e não é online. Por outro lado, não podemos confundir a educação online só com cursos pela Internet e somente pela Internet no modo texto (MORAN, 2003, p. 41).

Tal percurso expressa que não se pode ignorar a educação online enquanto dinâmica da prática social (interação comunicativa por redes e a facilidade de ver e agir interconectados), pois nela habita a força da ressignificação da palavra, frente à velocidade assustadora das informações. Explorar narrativas e realizar performances no campo movediço da educação é sempre um ato repleto de ameaças, descobertas, entusiasmo, intencionalidades, para formar leitores, para construir significados e fazer a leitura do mundo, da "palavra mundo" (FREIRE, 1989).O propósito de uma pedagogia da performance online implica na atitude de rever a postura do professor diante do conhecimento, da diversidade da vida e do outro, numa ambiguidade comunicacional, como uma exigência para que se construa novas práticas de interface interativas, participativas e colaborativas em constante transformação. Segundo Goffman (1975), o homem em sociedade age como um ator diante de seu público, desempenhando diferentes papéis sociais e buscando controlar, de certa forma, as impressões que os outros possam fazer de sua pessoa. Sempre que interagimos utilizamos formas variadas de percepção para dialogar com os outros, seja em uma lista eletrônica de discussão no Moodle, no Skype, no Facebook ou no celular. A partir do momento em que nos colocamos na presença do outro, elaboramos e desempenhamos um personagem de modo a causar uma determinada impressão e, por isso, é sensivelmente influenciada pela percepção que fazemos dos outros (alter dirigidas, nas curtidas e na relação com a figura do outro dos espaços virtuais).

Paradoxalmente, na sociedade otimizada pelo desempenho (de um professor-máquina, autômato), "o explorador é ao mesmo tempo explorado. Agressor e vítima não podem mais ser distinguidos. Essa autorreferencialidade gera uma liberdade paradoxal que, em virtude das estruturas coercitivas que lhe são inerentes, se transforma em violência" (HAN, 2017, p. 30).

Em nome de palavras falsamente emancipatórias, como empreendedorismo, ou de eufemismos perversos como flexibilização, cresce o número de autônomos, os tais PJs (Pessoas Jurídicas), livres apenas para se matar de trabalhar. Os autônomos são autômatos, programados para chicotear 
a si mesmos. E mesmo os empregados se autonomizam porque a jornada de trabalho já não acaba. Todos trabalhadores culpados porque não conseguem produzir ainda mais, numa autoimagem partida, na qual supõem que seu desempenho só é limitado porque o corpo é um inconveniente (BRUM, 2016, online).

No caso da pedagogia online, permanecemos sempre conectados e quanto mais exaustos e correndo melhor a nossa performance, mesmo que para isso estejamos medicados e submetidos a uma velocidade desumana que adoece e causa o mal-estar docente pela sensação de permanente ameaça, paranoia e ativismo. "A autoexploração é muito mais eficiente que a exploração estranha, pois caminha de mãos dadas com o sentimento de liberdade" (o primeiro sintoma do Burnout é a euforia ao trabalho), que acaba nos vitimando (HAN, 2017, p. 115). A urgência dos estímulos e repressões ao mesmo tempo de ações virtuais faz com que os sujeitos ressaltem aspectos de si que se aproximam das expressões de suas imagens idealizadas. Tais relações são capazes de revelar traços de personalidade e pistas de como o sujeito gostaria de ser percebido no espaço compartilhado virtualmente, no qual também diversos atores constroem a sua representação e impressões das situações sociais divulgadas.

Nos cursos presenciais, a ação de ensino é focada em momentos de encontro face a face entre alunos e professor e os recursos telemáticos podem ser um complemento ou um recurso de ensino potencializador de certas aprendizagens. A EaD implica na separação espaço temporal entre aluno e professor cujo modelo comunicacional, ao longo da história dela, priorizou os meios de comunicação de massa (mídia impressa, rádio, TV) e mais recentemente a comunicação online. As práticas de $\mathrm{EaD}$ frequentemente centram sua concepção pedagógica no autoaprendizado ou no estudo individualizado sustentado modestamente por tutores e materiais de apoio muito mais na função de tira-dúvidas (CALIXTO, 2012, p. 43).

Essa atuação pedagógica carrega alguns equívocos moldados pelas práticas conservadoras de tomar a máquina como modelo à produção do conhecimento, que vincula os valores dos atores hegemônicos e a onipresença do capital como metáfora inspiradora. Justamente esta dependência à unidirecionalidade de treinamentos e capacitações necessita de novas interfaces com o saber, dada a construção das relações de aprendizagem social nessa prática diversificada, de uma "proposição pedagógica e comunicacional centrada 
na interação" (CALIXTO, 2012). Cabe esclarecer que falta aos professores uma experiência performativa que dê conta da dimensão subjetiva, objetiva e social da comunicação (articulando cognição, racionalidade, afetividade e sensibilidade), de modo a desenvolver uma atuação que favoreça as interações dialógicas e aprendentes, concretizando a ação performativa global, que propõe uma abordagem epistemológica reconfigurada na experiência, que supera a transmissão individualista (protótipo da alienação social) e alarga os próprios limites do ato pedagógico em rede.

\section{O potencial de visibilidade das interações sociais à educação}

Dentro de um quadro convencional movimentado pelos meios empobrecidos do poder, do dinheiro e da burocratização das estruturas sociais, nada parece depor a favor da ideia de que em uma atitude não objetivante, ou seja, na atitude performativa os participantes da comunicação possam extrair a força do questionamento e da crítica intramundana no interagir e trabalhar entre mundos digitais. Diante do aprofundamento do poder das redes é chegada a hora de se enfrentar diretamente as questões que emergem das descontinuidades e dos fenômenos da performance educativa. A ideia de performance digital tem uma riqueza de sentidos que extrapola seu significado contextual de fazer algo, contaminando as margens do pensar sobre as palavras e as coisas. Uma rede de performances pedagógicas só poderia acontecer na linguagem que é o espaço da criação sensível, é o lugar da ressignificação dos (hiper)textos (linguísticos, visuais, gestuais, sonoros e sincréticos) em um outro conhecimento possível, aflorando estados de imprevisibilidade, pois na performance sempre há transformação educativa.

Desse ponto de vista, a performance no mundo digital não representa um instante pontual, mas uma porta sempre aberta para a superação do tempo (que nos leva tanto ao passado como ao futuro) e permite um entrecruzamento completo entre as temporalidades, assim como inversões das relações de tempo, permitindo ao passado fazer-se presente e o presente ser um eco do passado. Já o futuro está entre nós como a possibilidade do viver o que perdemos no passado. As dinâmicas em rede como uma ação dialógica têm repercussões sociais e performativas na educação, pois vão ao encontro da partilha do sensível e da exteriorização dos aspectos sociais, éticos e culturais próprios da construção de relações e memórias coletivas. De acordo com Casalegno (2006, p. 32), 
É essa forma de exteriorização e de partilha de sensações e de informações em rede que modela a memória coletiva e viva das comunidades a que pertencemos e que nos permite, em última instância, dar sentido à nossa existência: criar associações, formar comunidades e partilhar as emoções em comum.

É preciso olhar para as tecnologias digitais não como um objeto neutro e alheio ao humano, mas como polarizações da palavra efêmera, transitória, de processos interativos com modestos estímulos, que podem despertar para a conversação animada (por vozes discordantes), para se conhecer e potencializar a criação interconectada, num mundo marcado pelas controvérsias e compreensões distintas entre atores sociais. Diálogos em rede também revelam nuances até agora desconhecida da linguagem oral e escrita, por intermédio de suas interações mútuas, em conexões e movimentos que se desdobram em paradoxos, como "um dispositivo pelo qual se ordena a própria comunicação e a memória” (PEREIRA, 2011, p. 89).

Nessa perspectiva, podemos referir a vontade de ação, a integração de saberes, em termos de agir dialógico, problematizador, ético, estético e político, como caraterísticas principais de uma educação performativa online. Quando a sociedade sofre mudanças radicais em termos tecnológicos como acontece na atualidade, urge a necessidade de ressignificação e revisão dos processos formativos e educativos para atender aos desafios da comunicação virtual e seus sentidos, tendo em vista os encurtamentos das distâncias no mundo. A educação online é responsável por estender as possibilidades de contato e trocas de conhecimentos, de descoberta das diferenças, de preservação da diversidade, de aprendizagem aberta e interativa no mundo da cultura, da arte e da ciência, que pode ser reconstituída na totalidade da comunicação digital. No entanto, "as utopias e os conceitos de produção colaborativa, inteligência coletiva e sabedoria das multidões não podem descambar numa interpretação capciosa de apagamento de diferenças" (PRIMO, 2013, p. 23).

A realidade virtual fornece razões de conviver com novas interfaces do corpo e do cognitivo, mas ao mesmo tempo pode se manifestar como algo frio, instável, passivo, com valor em si, insensível, algo estranho à significação, emoção e valor humano (LÉVY, 2005). Acrescentamos a isso que as imagens e as construções linguísticas também podem fornecer circuitos de comunicação artificiais, instrumentalizados e instituídos. As verdadeiras relações e interfaces com o mundo são construídas entre os atores sociais que inventam, produzem, utilizam e interpretam as tecnologias, pois dependem do que os homens fazem com ela na ambivalência e multiplicidade de projetos. Vale dizer que os computadores pessoais aumentaram as capacidades performativas dos sujeitos, além de serem instrumentos de poder, de ação de ideias, utopias, interesses e jogos de linguagem. 
A hipótese que levanto é que a cibercultura leva a copresença das mensagens de volta a seu contexto como ocorria nas sociedades orais, mas em outra escala, em uma órbita completamente diferente. [...] Ela se constrói e se estende por meio da interconexão das mensagens entre si, por meio de sua vinculação permanente com as comunidades virtuais em criação, que lhe dão sentidos variados em uma renovação permanente (LÉVY, 2005, p. 15).

Esse canal de comunicação revela que "é virtual aquilo que existe apenas em potência e não em ato, o campo de forças e de problemas que tende a resolverse em uma atualização" (LÉVY, 2005, p. 47; grifos do autor). Desse modo, o virtual é o desterritorializado assim como uma palavra pronunciada, que é fonte inesgotável de atualizações e capaz de gerar diversas manifestações imprevisíveis em distintos momentos que constituem uma comunicação interconectada. "As realidades virtuais podem colocar em jogo a visão, a audição, o tato e a cinestesia (sentido interno dos movimentos do corpo)", pois nessas realidades o saber está em jogo na comunicação e esta interatividade remete ao virtual (LÉVY, 2005, p. 62). Tais tecnologias na educação causam uma sedução, uma ação performativa enquanto obra emergente, pois a humanidade reconhece a pluralidade dos saberes no fluxo vivo das interações e recriações contínuas. Assim, "cada jogador contribui para construir o universo no qual participa sob o aspecto do 'personagem' que ele encarna" (LÉVY, 2005, p. 105).

Podemos dizer que os limites dos usos das linguagens projetadas pelas tecnologias digitais denotam os limites de nossos mundos, de nossos contextos, embora não exista uma forma básica da linguagem, mas uma pluralidade. Assim, novos jogos de linguagem surgem (outros desaparecem) como algo vivo, dinâmico, que só pode ser entendido a partir da integração das formas de vida. Nesse contexto, a performance do professor online pode contribuir para o reconhecimento dos saberes na diversidade humana dos jogos de linguagem, um projeto fundamentalmente humanístico, incentivando e mobilizando novas criações cooperativas dos atores sociais nos mundos inter-relacionais. Afinal de contas, nos intensos processos educativos diversos atores, projetos e interpretações estão em luta de forças, conflitos e permanente tomada de decisão na pragmática linguística, que "nos confirma o caráter aberto do devir tecnológico e de suas implicações sociais" (LÉVY, 2005, p. 200).

Nessa perspectiva, cada dispositivo tecnológico se associa a certas situações de uso que é preciso investigar, pois se identificam com as relações e os processos de interdependência formativa e dialética e, ao mesmo tempo, com a eficácia do mercado para extrair dos sujeitos a maior produtividade possível. 
Embora as tecnologias participem como coadjuvantes das ações em curso, envolvendo multidões ao vivo (pela mediação online) e dando as condições do jogo comunicativo, não tem em si a dimensão intersubjetiva de um ator social, capaz de agir, modificar, atualizar a realidade e se fazer presente em termos performativos. O sentido performativo da educação online permite refletir sobre o processo de decisão, intercomunicação e humanização, tornando efetiva a racionalidade humana, a partir de uma perspectiva englobante que assume as dimensões epistemológicas, sociais, psicológicas, tecnológicas e educacionais do agir, visando assim à transformação dos atores envolvidos no processo. "Em seu escrito Vita activa, Hannah Arendt procura reabilitar a vida ativa contra o primado tradicional da vida contemplativa, rearticulando-a em seu múltiplo desdobramento interno. Em sua opinião, a vita activa foi degradada de forma injusta na tradição à mera agitação" (HAN, 2017, p. 39).

Acrescenta-se à análise que a sociedade do trabalho aniquila toda a possibilidade de agir (sensível, ético, estético e singular), uma vez que degrada o sujeito a "um animal trabalhador online". Por este viés, "quanto mais se troca de identidade, mais se impulsiona a produção. A sociedade disciplinar industrial depende de uma identidade firme e imutável, enquanto que a sociedade do desempenho não industrial necessita de uma pessoa flexível, para poder aumentar a produção" (HAN, 2017, p. 97). Verificamos nas ações virtuais uma certa deterioração e desorientação do mundo vivido face à brutalidade de um sistema regido pela competição predadora, que substitui a sensibilidade performativa por impessoais sistemas eletrônicos de comunicação imediatista, para o desempenho de uma função multitarefas e distante, perdendo, muitas vezes, o próprio caráter criativo e pessoal expresso de maneira performativa. "A hiperatividade é, paradoxalmente, uma forma extremamente passiva de fazer, que não admite mais nenhuma ação livre. Radica-se numa absolutização unilateral da potência positiva" (HAN, 2017, p. 57-58).

Vale destacar que a organização de um processo conversacional em sua forma mais simples é uma "unidade mínima de diálogo" entre os participantes em interação mútua (GOFFMAN, 1975). É justamente nesse sentido que o conceito de "inteligência coletiva e leitura crítica da realidade" servem de referência a processos de educação online, que envolve a reconfiguração crítica das interações, cuja repercussão decorre do trabalho criativo e colaborativo dos próprios atores envolvidos (LÉVY, 2005; FREIRE, 1989). Para aprender a dizer a palavra, é necessária uma leitura crítica do mundo sociotécnico de controle, o que implica levar em consideração as ações performativas desenvolvidas e articuladas à autocompreensão das interações sociais. A performance pedagógica exige presença e reflexão sobre a atuação, tendo em vista a reelaboração de ações e motivações conjuntas, além de ousar com as possibilidades trazidas 
pelas interações com as tecnologias digitais. Enquanto processo contraditório e complexo a performance instaura no movimento da compreensão que se abre para o conhecimento em reinvenção. A performance pedagógica "é um processo de autoformação e de criação transformadora”, não sendo mecânica e predefinida, mas que exige a presença online na $\mathrm{EaD}$, sendo uma condição de possibilidade à instauração de processos comunicativos em (re)construção das formas de apreender o mundo e de educar (CONTE, 2014, p. 543). A performance pedagógica refere-se a novos papéis sociais assumidos à reconstrução e à associação de conhecimentos e uma constante reconfiguração do professor nessa cultura da interface, mediada por tecnologias em rede.

Tudo indica que o problema da exclusão tecnológica, o mau uso da técnica e a sua dimensão mercadológica na educação não são as únicas questões relativas às patologias do ensino online, pois a debilidade do pensar desafiador constitui a negação do performativo. A ideia de performance online só se realiza efetivamente na convergência da linguagem e mediante a presença do outro no mundo, da mesma forma como uma peça teatral ganha sentido e vida se existir um público. A presença em ambientes virtuais também não é estática, mas transforma a própria subjetividade e sociabilidade, a partir do olhar do outro, e isso se relaciona com a lógica do "imperativo da visibilidade" (SIBILIA, 2008). Essa subjetividade exteriorizada no perfil virtual facilita o acesso às vitrines midiáticas e passa a ser reativa ao olhar do outro, uma vez que é nessa interface que ganha realidade ou gera a desilusão, caso não encontre o olhar do outro que o realiza. "Esses instrumentos de autoestilização agora se encontram à disposição de qualquer um", permitindo que as pessoas possam transformar sua vida particular num espetáculo - única fonte de prazer e felicidade que resta na cultura do mercado (SIBILIA, 2008, p. 233). O fato de expor o cotidiano em pautas que envolvem a adoção de práticas que contemplam o bem-estar e a autoestima colabora para que suas performances sejam aceitas e reconhecidas pelos outros no momento presente, mas ao mesmo tempo, normas e valores se desestabilizam.

Contudo, para Habermas (1999), a linguagem é um ato de invenção e criação de situações que tanto pode ser utilizada como meio de transmissão de informações (agir estratégico) quanto como meio de integração social (agir comunicativo). Por essa via, a sociedade do capitalismo dificulta a problematização das questões através de dogmatismos e das palavras do estrangeiro (descontextualizadas), porque o debate sobre a instrumentalidade permanece incompreensível aos leigos, assegurando a manutenção de uma postura técnica e especializada. Desse ponto, reconhecemos que a institucionalização dos discursos constitui uma das inovações mais difíceis e perigosas da história da humanidade, porque acaba submetendo todas as dimensões da atividade humana ao agir com relação a fins. Na medida em que "se institucionaliza a introdução de novas tecnologias e de novas estratégias", 
isto é, "institucionaliza-se a inovação enquanto tal" cumpre, a tecnociência, o papel de legitimar a dominação como apropriação de conhecimentos operacionais de pensar (HABERMAS, 1990, p. 62). O desenvolvimento e a determinação da sociedade trazem a necessidade de crítica permanente para revelar as raízes desse movimento dialético com limitações e crises. Aliás, a pedagogia online não pode recair em um deslumbramento discursivo, que impede o processo formativo de questionar e dialogar com as diferenças (pensar em seu devir), descobrindo assim as condições para poder expressar o conflito como contradição capaz de despertar novas experiências performativas. Por essa via, impõe-se o sentido performativo de ação viva no diálogo aberto com o mundo, contrariando a mera apropriação e precisão instrumental, trazendo à educação o diferenciado, a crítica subversiva, de forma a humanizar as formações e resistir à homogeneização do agir, tendo nessa postura a possibilidade de reconciliação com o concreto sensível.

\section{Considerações finais}

Para um professor não acostumado a ressignificar e a questionar as tecnologias digitais nos contextos educativos e midiáticos, analisar as implicações e inferências desse movimento na efetividade da performance docente é um desafio complexo, no sentido de despertar a autocompreensão da própria experiência pedagógica da pluralidade. Há ambiguidades e contradições nesse campo de ação performático, fluído e intenso, onde vivemos em mais de um mundo e somos compelidos a nos sintonizar entre a obsolescência ou a atualização de mecanismos globais e na dialética performativa da ação e reflexão. As transições e entrelaçamentos de mundos nos incitam a performar a própria atuação na realidade como forma de dar visibilidade a modos de vida que aprendemos há pouco tempo. A proliferação das redes sociais exige dos professores o exercício do estranhamento e de resistência para ensaiar novas provocações educativas online no engajamento para despertar a produção de significados e refutações, numa lógica que opere no sistema nervoso da digitalização. O diálogo das culturas remete a paradoxos que exigem desvelar os limites da epistemologia da performance, como um projetar-se no mundo, através do obrar-se, que sempre diz algo e nos confronta, nos faz pensar que compreender uma ação performativa exige o encontro consigo mesmo e a autocompreensão do mundo. Ou seja, a experiência digital assim como a dimensão social da performance docente transforma o sujeito e é uma forma de linguagem aberta e educativa na própria ação, visto que carrega a capacidade de educabilidade e uma expressividade enigmática. 
As performances docentes que não passam pelo crivo da crítica sensível do mundo digital ou acompanham uma espécie de perfectibilidade inquestionável e ilusória das tecnologias beiram o abismo das incompreensões estéticas e da incapacidade de problematizar as experiências digitais. As interações mediadas por computador vieram demonstrar que a educação precisa reconhecer e performar novas produções de conhecimentos, dando visibilidade à democratização e às pesquisas dos processos comunicativos, compreendendo as relações contemporâneas em toda sua complexidade no mundo. Os espaços de expressão online são construídos e performados na relação com os outros, tornando compartilhável imagens pessoais e mensagens num contexto de interesses específicos. Sem sombra de dúvidas, as práticas sociais de educar congregam o dizer, o fazer, o interagir, no sentido ético, estético e técnico, bem como as inquietações e limites do conhecimento performativo em rede, isto é, formativo e expressivo da comunicação humana (CONTE, 2014). Pensar a performance do professor online implica reconhecer que as fronteiras corporais se borram nas experiências da realidade virtual, visto que "o nosso corpo habita o mundo (espaço e o tempo virtual), no perpétuo vir a ser e é comparado a uma obra de arte - um nó de significações vivas e mediadoras de um mundo" (MERLEAU-PONTY, 1994, p. 210).

O horizonte da educação necessita de margens antecipatórias de posturas comunicativas para explorar as brechas do sistema e dos discursos empresariais, permitido assim recriar e ressignificar conhecimentos, para resolver os problemas no engajamento com a práxis social. Trata-se de mobilizar uma performance em que a tecnologia não esteja em desconexão ou em desequilíbrio com a imaginação criadora da vida humana. As inovações técnicas ou sociais não se esgotam nos objetos, mas deveriam ser incorporados à formação e à inclusão da sensibilidade para que o sujeito exerça sua capacidade perceptiva e transformadora de agir na relação com o outro no mundo. Talvez as interfaces que mantém abertas as dimensões do intervir humano enquanto movimento e metamorfose no mundo podem contribuir ao esforço expressivo e imaginativo da performance pedagógica online. Quanto mais associações, melhores são as perspectivas problematizadoras para mexer em nossa sociedade e transformar conhecimentos. Parece que a performance educativa necessita reencontrar a força relacional e a emoção da palavra, nessa plasticidade dos poderes ligados ao mundo virtual enquanto presença viva, na relação dialética de orientação para o nosso horizonte mundano. A rigor, as perguntas lançadas no texto não tiveram a pretensão de findarem uma verdade acabada e única, mas de abrir outras possibilidades de reflexão que pode se expandir a partir de releituras e pesquisas, para tratar esse tema contraditório e multifacetado da performance docente em meio a cultura digital. 


\section{REFERÊNCIAS}

ADORNO, Theodor L. W. Educação e Emancipação. Rio de Janeiro: Paz e Terra, 1995. ANDRÉ, Marli Eliza D. A. de. O papel da pesquisa na formação e na prática dos professores. 8. ed. Campinas: Papirus, 2008.

BRUM, Eliane. Exaustos-e-correndo-e-dopados. Na sociedade do desempenho, conseguimos a façanha de abrigar o senhor e o escravo no mesmo corpo. El País, Coluna, 04 jul. 2016. Disponível em: http://brasil.elpais.com/brasil/2016/07/04/ politica/1467642464_246482.html. Acesso em: 19 mar. 2020.

CALIXTO, Aldeci C. Docência universitária: dimensões didáticas da prática pedagógica. 2012. 212 f. Tese (Doutorado em Educação) - Universidade Federal de Uberlândia, Uberlândia, Minas Gerais, 2012.

CASALEGNO, Federico. Memória cotidiana: comunidade e comunicação na era das redes. Porto Alegre: Sulina, 2006.

CONTE, Elaine. Aporias da performance na educação. Revista Brasileira de Educação, v. 18, n. 52 , jan./mar. 2013.

CONTE, Elaine. Tempo e performance no trabalho docente. Revista Educação, Santa Maria, v. 39, n. 31, set./dez. 2014.

FERREIRA, Giselle M. dos S.; ROSADO, Luiz Alexandre da S.; CARVALHO, Jaciara de S. (org.). Educação e Tecnologia: abordagens críticas. Rio de Janeiro: SESES, 2017.

FLUSSER, Vilém. Los gestos: fenomenologia y comunicación. Barcelona: Editorial Herder, 1994.

FREIRE, Paulo. A importância do ato de ler: em três artigos que se completam. São Paulo: Autores associados: Cortez, 1989.

GOFFMAN, Erving. A representação do eu na vida cotidiana. Petrópolis: Vozes, 1975.

HABERMAS, Jürgen. Teoría de la Acción Comunicativa II: Crítica de la Razón Funcionalista. Madrid: Taurus, 1999.

HABERMAS, Jürgen. Pensamento pós-metafísico. Rio de Janeiro: Tempo Brasileiro, 1990.

HAN, Byung-Chul. Sociedade do cansaço. Tradução de Ênio Paulo Giachini. 2. ed. Petrópolis, RJ: Vozes, 2017.

LE BRETON, David. Paixões ordinárias. Petrópolis, RJ: Vozes, 2009.

LÉVY, Pierre. Cibercultura. 5. ed. Tradução de Carlos Irineu da Costa. São Paulo: Ed. 34, 2005.

MALLMANN, Elena Maria. Mediação Pedagógica em Educação a Distância: cartografia da performance docente no processo de elaboração de materiais didáticos. 2008. 304 f. Tese (doutorado em Educação) - Universidade Federal de Santa Catarina, Florianópolis, 2008. 
MERLEAU-PONTY, Maurice. Fenomenologia da Percepção. Trad. Carlos A. R. Moura. São Paulo: Martins Fontes, 1994.

MORAN, José M. Contribuições para uma pedagogia da educação online. In: SILVA, Marco (org.). Educação online: teorias, práticas, legislação, formação corporativa. São Paulo: Loyola, 2003.

NÓVOA, António. Nada será como antes. Revista Pátio, Porto Alegre, n. 72, p. 18-21, nov./jan. 2015.

PEREIRA, Vinícius A. Estendendo McLuhan: da aldeia à teia global. Porto Alegre: Sulina, 2011.

PRIMO, Alex (org.). Interações em rede. Porto Alegre: Sulina, 2013.

RECUERO, Raquel. A conversação em rede. Porto Alegre: Sulina, 2012.

SÁNCHEZ GAMBOA, Silvio. Projetos de pesquisa, fundamentos lógicos: a dialética entre perguntas e respostas. Chapecó: Argos, 2013.

SANTAELLA, Lucia. Intersubjetividade nas redes digitais: repercussões na educação. In: PRIMO, Alex (org.). Interações em rede. Porto Alegre: Sulina, 2013, p. 33-47.

SIBILIA, Paula. O Show do Eu: a intimidade como espetáculo. Rio de Janeiro: Nova Fronteira, 2008.

SIBILIA, Paula. O universo doméstico na era da extimidade: nas artes, nas mídias e na internet. Revista ECOPÓS - Arte, tecnologia e mediação, Rio de Janeiro, v. 18, n. 1, p. 132-147, 2015.

SIDI, Pilar M.; CONTE, Elaine. A hermenêutica como possibilidade metodológica à pesquisa em educação. Revista Ibero-Americana de Estudos em Educação, Araraquara, v. 12 , n. 4 , out./dez. 2017.

Texto recebido em 24/10/2019.

Texto aprovado em 19/03/2020. 